\title{
PROFIL KEMAMPUAN KOGNITIF MAHASISWA TADRIS IPA IAIN PALU PADA MATA KULIAH KONSEP DASAR IPA
}

\author{
Arda \\ Program Studi Tadris Ilmu Pengetahuan Alam, FTIK, Institut Agama Islam Negeri Palu \\ arda@iainpalu.ac.id
}

\begin{abstract}
ABSTRAK
Penelitian ini merupakan penelitian deskriptif yang bertujuan untuk mengetahui profil kemampuan kognitif mahasiswa Tadris IPA IAIN Palu pada mata kuliah Konsep Dasar IPA. Instrumen penelitian berupa soal pilihan ganda yang mengacu pada enam level Taksonomi Bloom revisi. Hasil analisis data menunjukkan bahwa persentase kemampuan kognitif mahasiswa Tadris IPA pada kategori sangat tinggi sebesar 5,6\%, tinggi sebesar $72,2 \%$, sedang sebesar $16,7 \%$ dan rendah sebesar 5,6\%. Mahasiswa Tadris IPA memiliki kemampuan mengingat (C1) sebesar 86\%, memahami (C2) sebesar 72\%, mengaplikasikan (C3) sebesar 61\%, menganalisis (C4) sebesar 77\%, mengevaluasi (C5) sebesar 42\% dan mencipta (C6) sebesar 6\%. Mahasiswa Tadris IPA memiliki keterampilan berpikir tingkat rendah (LOTS) lebih tinggi dibandingkan keterampilan berpikir tingkat tinggi (HOTS). Oleh karena itu, perlu dilakukan pembelajaran yang dapat meningkatkan kemampuan HOTS mahasiswa Tadris IPA.
\end{abstract}

Kata Kunci : kemampuan kognitif, Taksonomi Bloom, Konsep Dasar IPA.

\begin{abstract}
This research is descriptive research. It aims to find out profile of cognitive abilities students of Tadris IPA IAIN Palu who programmed the Basic Concepts of Natural Sciences courses. The research instrument was multiple choice questions that refers to the six revised Bloom's Taxonomy level. The results of data analysis showed that the percentage of cognitive abilities students of Tadris IPA category very high were $5.6 \%$, high were $72.2 \%$, medium were $16.7 \%$ and low were $5.6 \%$. Students of Tadris IPA have the ability remembering (C1) were $86 \%$, understanding (C2) were $72 \%$, applying (C3) were $61 \%$, analyzing (C4) were $77 \%$, evaluating (C5) were $42 \%$ and creating (C6) were $6 \%$. Students of Tadris IPA have Lower Order Thinking Skills (LOTS) higher than Higher Order Thinking Skills (HOTS). Therefore, learning needs to be done that can improve the ability of HOTS students of Tadris IPA.
\end{abstract}

Keywords : cognitive ability, Bloom's Taxonomy, Basic Concepts of Natural Sciences

\section{PENDAHULUAN}

Konsep Dasar IPA merupakan mata kuliah yang membahas konsep-konsep dasar dalam bidang Ilmu Pengetahuan Alam (IPA). IPA secara garis besar dapat dibedakan menjadi 3 bidang yaitu Fisika, Kimia dan Biologi (Trianto, 2011). IPA adalah pengetahuan yang sistematis yang mengkaji tentang alam semesta, benda-benda yang ada di permukaan dan perut bumi dan juga luar angkasa baik yang dapat diamati secara langsung maupun yang tidak dapat amati oleh indera (Maidarly, 2018). 


\section{Koordinat Jurnal Pembelajaran Matematika dan Sains}

Vol. 1, No. 1, Juli 2020, Hal. 33-37

Prinsip pembelajaran yang berpusat pada mahasiswa di perguruan tinggi diterapkan agar mahasiswa aktif dalam proses pembelajaran (Machin, 2014). Prinsip tersebut dalam pembelajaran Konsep Dasar IPA menjadikan mahasiswa harus mampu menemukan masalah yang terjadi di lingkungan sekitar dan memecahkan masalah tersebut secara mandiri.

Mahasiswa dalam pembelajaran Konsep Dasar IPA diharapkan memiliki kemampuan berpikir, bekerja, bersikap ilmiah dan berkomunikasi sebagai kecakapan hidup. Pembelajaran ditekankan pada pemberian pengalaman belajar secara langsung (Retno \& Yuhanna, 2016). Oleh karena itu, setiap akhir proses pembelajaran kemampuan mahasiswa khususnya ranah kognitif dapat meningkat.

Kemampuan mahasiswa ranah kognitif dapat diukur dengan menggunakan Taksonomi Bloom revisi. Taksonomi Bloom revisi mengubah urutan dua kategori kognitif dengan menempatkan mencipta sebagai kategori paling kompleks (Gunawan \& Palupi, 2012). Taksonomi Bloom revisi ranah kognitif terdiri atas enam level yaitu mengingat (C1), memahami (C2), mengaplikasikan (C3), menganalisis (C4), mengevaluasi (C5) dan mencipta (C6). Tiga level pertama merupakan Lower Order Thinking Skills (LOTS) dan tiga level berikutnya Higher Order Thinking Skills (HOTS) (Anderson \& Krathwohl, 2010).

Mahasiswa Tadris IPA harus menggali dan melatih kemampuan kognitifnya. Banyak cara yang dapat dilakukan untuk meningkatkan kemampuan kognitif. Salah satunya dengan mengembangkan pembelajaran berorientasi pada Higher Order Thinking Skills (HOTS) atau keterampilan berpikir tingkat tinggi (Ariana, Pudjiastuti,
Bestary, \& Zamroni, 2018). HOTS digunakan sebagai upaya untuk meningkatkan kualitas pembelajaran dan juga kualitas lulusan. Mahasiswa Tadris IPA disiapkan sebagai lulusan yang siap kerja tentunya harus memiliki kemampuan kognitif yang baik.

Berdasarkan uraian di atas maka perlu dilakukan analisis profil kemampuan kognitif mahasiswa Tadris IPA pada mata kuliah Konsep Dasar IPA. Mata kuliah tersebut sangat penting bagi mahasiswa karena membahas konsep dasar yang sangat bermanfaat pada mata kuliah IPA lainnya.

\section{METODE PENELITIAN}

Metode yang digunakan dalam penelitian ini adalah metode deskriptif. Subjek penelitian adalah mahasiswa Tadris IPA IAIN Palu semester II yang memprogramkan mata kuliah Konsep Dasar IPA. Instrumen penelitian menggunakan soal pilihan ganda yang mengacu pada enam level Taksonomi Bloom revisi.

Skor kemampuan kognitif mahasiswa dihitung menggunakan teknik penskoran dengan koreksi terhadap jawaban tebakan (Sumaryanta, 2015).

$$
\text { Skor }=\left(\frac{\mathrm{B}-\frac{\mathrm{S}}{\mathrm{P}-1}}{\mathrm{~N}}\right) \times 100
$$

Keterangan:

$\mathrm{B}=$ banyak butir soal yang dijawab benar

$\mathrm{S}$ = banyak butir soal yang dijawab salah

$\mathrm{P}=$ banyaknya pilihan jawaban tiap butir

$\mathrm{N}$ = banyaknya butir soal

Butir soal yang tidak dijawab diberi skor 0 .

Hasil perhitungan yang diperoleh selanjutnya dikelompokkan berdasarkan kategori pada Tabel 1 (Wiyoko \& Aprizan, 2020).

Tabel 1. Persentase Kemampuan Kognitif

\begin{tabular}{lc}
\hline Kategori & Persentase \\
\hline Sangat tinggi & $80 \%<\mathrm{P} \leq 100 \%$ \\
Tinggi & $60 \%<\mathrm{P} \leq 80 \%$ \\
Rata-rata (sedang) & $40 \%<\mathrm{P} \leq 60 \%$ \\
Rendah & $20 \%<\mathrm{P} \leq 40 \%$ \\
Sangat rendah & $0 \%<\mathrm{P} \leq 20 \%$ \\
\hline
\end{tabular}

\section{HASIL DAN PEMBAHASAN}




\section{Koordinat Jurnal Pembelajaran Matematika dan Sains}

Vol. 1, No. 1, Juli 2020, Hal. 33-37

Pembelajaran Konsep Dasar IPA dilakukan dengan pendekatan kontekstual yang memanfaatkan lingkungan sekitar sebagai sumber belajar. Pembelajaran tersebut diharapkan dapat meningkatkan kemampuan kognitif mahasiswa Tadris IPA IAIN Palu yang berasal dari latar belakang pendidikan menengah atas yang beragam.

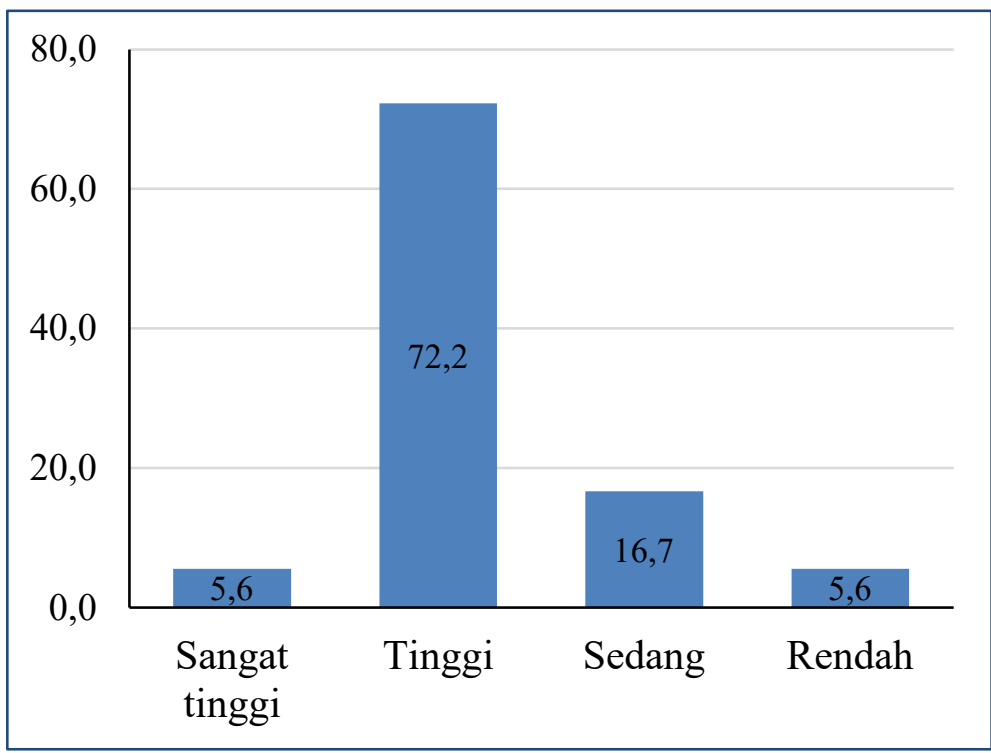

Gambar 1. Grafik Persentase Kemampuan Kognitif Mahasiswa Tadris IPA pada Mata Kuliah Konsep Dasar IPA

Adapun persentase kemampuan kognitif mahasiswa dapat dilihat pada Gambar 1. Hasil tersebut menunjukkan bahwa persentase kemampuan kognitif mahasiswa Tadris IPA pada mata kuliah Konsep Dasar IPA kategori sangat tinggi sebesar $5,6 \%$, tinggi sebesar $72,2 \%$, sedang sebesar $16,7 \%$ dan rendah sebesar 5,6\%. Adanya perbedaan tersebut dapat disebabkan oleh beberapa faktor antara lain perbedaan gaya belajar dan kemampuan daya tangkap materi yang diajarkan.

Aspek kemampuan kognitif mahasiswa secara rinci dapat dijelaskan sebagai berikut.

1. Kemampuan mengingat

Kemampuan mengingat berada pada level Lower Order Thinking Skills (LOTS). Mahasiswa yang memiliki kemampuan ini diharapkan dapat mengambil kembali pengetahuan yang dibutuhan dalam memori jangka panjang mereka.

Hasil analisis diperoleh tingkat kemampuan mengingat sebesar $86 \%$. Hal tersebut menunjukkan bahwa tingkat kemampuan mengingat mahasiswa Tadris IPA pada mata Kuliah Konsep Dasar IPA berada pada kategori sangat tinggi.

2. Kemampuan memahami

Kemampuan memahami berada pada level Lower Order Thinking Skills (LOTS). Mahasiswa yang memiliki kemampuan ini diharapkan dapat mengintegrasikan informasi yang baru dengan pengetahuan yang mereka miliki.

Hasil analisis diperoleh tingkat kemampuan memahami sebesar $72 \%$. Hal tersebut menunjukkan bahwa tingkat kemampuan memahami mahasiswa Tadris IPA pada mata Kuliah Konsep Dasar IPA berada pada kategori tinggi.

3. Kemampuan mengaplikasikan

Kemampuan mengaplikasikan berada pada level Lower Order Thinking Skills (LOTS). Mahasiswa yang memiliki kemampuan ini diharapkan dapat menerapkan prosedur dalam pemecahan masalah.

Hasil analisis diperoleh tingkat kemampuan mengaplikasikan sebesar $61 \%$. 


\section{Koordinat Jurnal Pembelajaran Matematika dan Sains}

Vol. 1, No. 1, Juli 2020, Hal. 33-37

Hal tersebut menunjukkan bahwa tingkat kemampuan mengaplikasikan mahasiswa Tadris IPA pada mata Kuliah Konsep Dasar IPA berada pada kategori tinggi.

4. Kemampuan menganalisis

Kemampuan menganalisis berada pada level Higher Order Thinking Skills (HOTS). Mahasiswa yang memiliki kemampuan ini diharapkan dapat menguraikan unsur-unsur penyusun suatu objek atau permasahan dan mampu menjelaskan keterkaitan unsur-unsur tersebut.

Hasil analisis diperoleh tingkat kemampuan menganalisis sebesar $77 \%$. Hal tersebut menunjukkan bahwa tingkat kemampuan menganalisis mahasiswa Tadris IPA pada mata Kuliah Konsep Dasar IPA berada pada kategori tinggi.

5. Kemampuan mengevaluasi

Kemampuan mengevaluasi berada pada level Higher Order Thinking Skills (HOTS). Mahasiswa yang memiliki kemampuan ini diharapkan dapat memberikan penilaian berdasarkan standar dan kriteria yang ada.

Hasil analisis diperoleh tingkat kemampuan mengevaluasi sebesar $42 \%$. Hal tersebut menunjukkan bahwa tingkat kemampuan mengevaluasi mahasiswa Tadris IPA pada mata Kuliah Konsep Dasar IPA berada pada kategori sedang.

6. Kemampuan mencipta

Kemampuan mencipta berada pada level Higher Order Thinking Skills (HOTS). Mahasiswa yang memiliki kemampuan ini diharapkan dapat menghasilkan suatu produk dengan melakukan penataan ulang beberapa unsur kedalam bentuk atau pola yang baru.

Hasil analisis diperoleh tingkat kemampuan mencipta sebesar 6\%. Hal tersebut menunjukkan bahwa tingkat kemampuan mencipta mahasiswa Tadris IPA pada mata Kuliah Konsep Dasar IPA berada pada kategori sangat rendah.

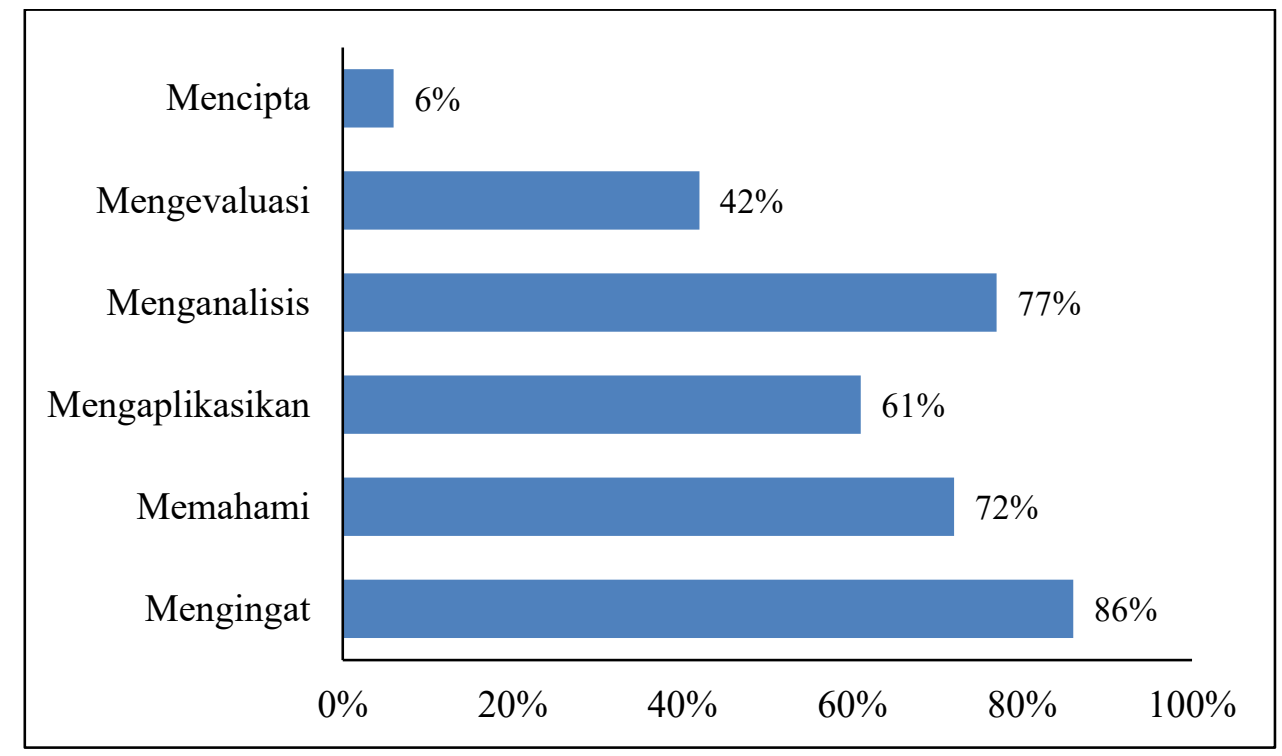

Gambar 2. Grafik Perbandingan Profil Kemampuan Kognitif Mahasiswa Tadris IPA pada Mata Kuliah Konsep Dasar IPA

Berdasarkan Gambar 2 dapat disimpulkan bahwa kemampuan kognitif mahasiswa Tadris IPA pada mata kuliah Konsep Dasar IPA paling tinggi berada pada kemampuan mengingat (86\%) sedangkan paling rendah berada pada kemampuan mencipta (6\%). Rata-rata kemampuan kognitif mahasiswa pada level Lower Order
Thinking Skills (LOTS) atau keterampilan berpikir tingkat rendah adalah $73 \%$. Rata-rata kemampuan kognitif mahasiswa pada level Higher Order Thinking Skills (HOTS) atau keterampilan berpikir tingkat tinggi adalah $41,7 \%$.

Hasil penelitian ini menunjukkan bahwa mahasiswa masih kurang dalam 


\section{Koordinat Jurnal Pembelajaran Matematika dan Sains}

Vol. 1, No. 1, Juli 2020, Hal. 33-37

keterampilan berpikir tingkat tinggi khususnya kemampuan berkreasi dalam menciptakan sesuatu yang baru. Mahasiswa belum mampu memadukan kemampuan mengingat, memahami, mengaplikasikan, menganalisis, mengevaluasi dan mencipta menjadi satu kesatuan. Oleh karena itu, diperlukan berbagai metode ataupun pendekatan agar seluruh kemampuan tersebut dapat dimiliki oleh mahasiswa.

\section{KESIMPULAN}

Kemampuan kognitif mahasiswa Tadris IPA IAIN Palu pada mata kuliah Konsep Dasar IPA level LOTS lebih tinggi dibandingkan HOTS. Hasil ini menunjukkan perlunya dilakukan pembelajaran untuk meningkatkan HOTS. Pembelajaran dengan menerapkan model-model pembelajaran ataupun penggunaan sumber belajar yang dapat mengintegrasikan kemampuan HOTS.

\section{DAFTAR PUSTAKA}

Anderson, L. W., \& Krathwohl, D. R. (2010). Kerangka Landasan untuk Pembelajaran, Pengajaran dan Asesmen (Revisi Taksonomi Pendidikan Bloom). Yogyakarta: Pustaka Pelajar.

Ariana, Y., Pudjiastuti, A., Bestary, R., \& Zamroni. (2018). Buku Pegangan Pembelajaran Berorientasi pada Keterampilan Berpikir Tingkat Tinggi. Jakarta: Direktorat Jenderal Guru dan Tenaga Kependidikan, Kementerian Pendidikan dan Kebudayaan.

Gunawan, I., \& Palupi, A. R. (2012). Taksonomi Bloom-Revisi Ranah
Kognitif: Kerangka Landasan untuk Pembelajaran, Pengajaran dan Penilaian. Premiere Educandum: Jurnal Pendidikan Dasar dan Pembelajaran, 98-117.

Machin, A. (2014). Implementasi Pendekatan Saintifik, Penanaman Karakter dan Konservasi pada Pembelajaran Materi Pertumbuhan. Jurnal Pendidikan IPA Indonesia, 28-35.

Maidarly. (2018). Peningkatan Aktivitas dan Hasil Belajar Peserta Didik pada Pembelajaran IPA dengan Menerapkan Pembelajaran Kooperatif Tipe Bermain Jawaban Kelas V SDN 29 Siguntur Muda Kecamatan Koto XI Tarusan. Jurnal Penelitian Guru Indonesia-JPGI, 8-14.

Retno, R. S., \& Yuhanna, W. L. (2016). Pembelajaran Konsep Dasar IPA dengan Scientific Inquiry untuk Meningkatkan Kemampuan Berpikir, Bekerja dan Bersikap Ilmiah pada Mahasiswa. Jurnal Pendidikan Biologi Indonesia, 1-9.

Sumaryanta. (2015). Pedoman Penskoran. Indonesian Digital Journal of Mathematics and Education, 181-190.

Trianto. (2011). Model Pembelajaran Terpadu. Jakarta: Bumi Aksara.

Wiyoko, T., \& Aprizan. (2020). Analisis Profil Kemampuan Kognitif Mahasiswa PGSD pada Mata Kuliah Ilmu Alamiah Dasar. IJIS Edu : Indonesian Journal of Integrated Science Education, 28-34. 